\title{
Determination of erosion equation factors of AISI1020 by experimental data
}

\author{
Mehdi Akhondizadeh ${ }^{1,{ }^{*}}$ and Nader Afkhami ${ }^{2}$ \\ ${ }^{1}$ Department of Mechanical Engineering, Sirjan University of Technology, Sirjan, Iran \\ ${ }^{2}$ Department of Mechanical Engineering, Sirjan Branch, Islamic Azad University, Sirjan, Iran
}

Received: 1 July 2019 / Accepted: 27 November 2019

\begin{abstract}
Erosive wear is material removal due to the impingement of granular flow. In the present work, the effects of influencing parameters including flow velocity, incidence angle and grain size on erosive behavior of AISI1020 subjected to a flow of $\mathrm{SiC}$ particles has been investigated by employing an erosion wear test machine. The experiments have been performed at the different values of impact angle, flow velocity and particle size. Two tests have been performed for every set of conditions and the average of them has been presented. Results showed that the erosive wear maximizes at the impact angles of $30^{\circ}$ and $45^{\circ}$. The flow of small particles resulted in more wear contrast to the large particles. Results also indicated that the influence of flow velocity was higher than the influence of impact angle and particle size. It means that minimizing the flow velocity results in more efficient results to reduce erosion. Moreover, the experimental data were used to determine appropriate coefficients for using in an erosion equation given by literature. New factors gave erosion evaluations which had appropriate accordance with the experimental data.
\end{abstract}

Keywords: Erosive wear / flow velocity / impingement angle / particle size / experiment / erosion equation coefficients

\section{Introduction}

Erosive wear influences the normal performance of machinery, especially in particle handling equipment in mineral complexes. The erosion is influenced by several factors including the surface properties such as hardness and roughness, eroding particle properties such as shape, size and hardness and environmental conditions such as impingement velocity, incidence angle and particle flux [1]. In several cases, experimental apparatus have been employed to study the erosive wear [1-4]. Pool et al. [1] studied the erosive behavior of the polymer composites and reported that the maximum wear occurs at $25^{\circ}-45^{\circ}$ impingement angle which is a quasi-ductile behavior. Tian and Addie [2] studied the erosive behavior of high chromium white iron and aluminum alloys by means of Coriolis wear testing machine. They reported that high chromium steel wear is made by sliding while the wear of aluminum samples is through the combination of sliding wear and low angle impact wear. Misra and Finnie [5] investigated the effect of particle size on erosion and twoand three-body abrasion. Bahadur and Badruddin [6] concluded that the erosion rate made by $\mathrm{SiC}$ and $\mathrm{Al}_{2} \mathrm{O}_{3}$

\footnotetext{
*m.akhondizadeh@sirjantech.ac.ir
}

increases with increasing the particle size up to a certain value but it is not true for $\mathrm{SiO}_{2}$ particles. In a relating research, Clark and Hrtwich [7] concluded that there is no fundamental change in the interaction between impacting erodent particles $(\mathrm{SiC})$ and the wearing surface with increasing particle size between 100 and $780 \mu \mathrm{m}$. Ruff and Ives [8] presented a method to measure the particle velocity in erosive wear experimental apparatus. Zhang et al. [9] studied numerically the erosion wear of fan impellers by computational fluid dynamics. They presented a bionic profile for impeller and studied its erosive wear behavior contrast to the standard impellers. The results showed that the bionic fan blade has lower erosion rate than the standard fan blade when the particle size is $20 \mu \mathrm{m}$. Shen et al. [10] explored the possibility to heal early stage erosion damage of $\mathrm{Cr}_{2} \mathrm{AlC}$ MAX phase subjecting to high air temperatures and erosive flows. Their experiments showed that high temperature oxidative conditions extend the lifetime of $\mathrm{Cr}_{2} \mathrm{AlC}$ MAX phase components subjected to erosive substances. Where the erosion wear occurs the question is the changing of which of influencing parameters lowers the erosion rate. However, the erosion is not a simple process to be predicted, but the predicting models are very welcomed. These relations include the factors which should be determined experimentally. In the present work, the effects of influencing parameters on the erosive wear of 


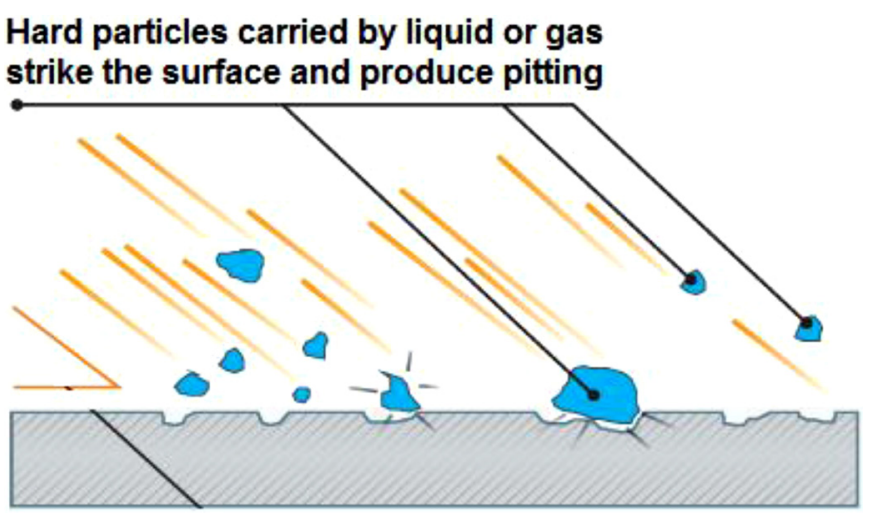

Figure 1. Schematic of impingement of particles to a surface causing the erosion wear.

AISI1020 steel has been investigated by employing an erosion wear test machine. The aim was evaluation of the erosive behavior of samples through the variation of impact angle, flow velocity and particle size. It was also tried to determine which of the parameters, among the mentioned factors, have the higher influence on the erosive wear. Moreover, the factors used for evaluation of erosive wear by theoretical relation given by Arabnejad et al. [11] are evaluated by experimental data for the present case.

\section{Erosive wear}

Erosive wear occurs due to the impingement of a granular dry or wet flow to a surface [12] as illustrated in Figure 1.

Eroding particles leave a cavity which may be due to the plastic deformation or due to the material removal in form of cutting or fatigue. Cutting is a sign of severity of the shear part of impact on the mating materials and fatigue is the result of the normal severity of impact. Materials don't have the same wear reaction to the shear and normal part of impact. It depends highly on their micro and macro material properties. Brittle materials experience micro cracks on the surface and radial macro cracks under the impact point. Ductile materials undergo the maximum shear stress beneath the contact point which propagates to the surface under the repletion of impact and is resulted in the fatigue wear. Since the mechanisms of wear may be different according to the material properties, the critical value of impact angle is not same for different materials. The effects of impact velocity and particle size on the erosion value are not identical for different materials. Severity of the shear part of impact is influenced highly by the factors such as the surface friction and roughness and the shape of the eroding particles. This form of wear produces longitudinal scratches which are the sign of wear due to tangential relative sliding. For surfaces which the shear part of impact is more intensive, the maximum erosion is observed at the impact angle lower than $40^{\circ}$ and for surfaces which the normal part of impact is more intensive the maximum erosion is experienced at the impact angles larger than $50^{\circ}$. Erosion is a problem which is widely encountered in elements such as industrial fan impellers and slurry handling pipes which handle the tiny grains. Since the repair and replacement of worn parts is usually a time consuming and costly activity, their optimization toward having the required performance with the minimum erosion will be welcomed. To have the minimum wear and damages, the influencing parameters on erosive wear should be determined and the knowledge of their effect value should be improved. Erosion is a complex phenomenon which is difficult to be predicted for multi-size slurries due to the dependency on the single granular size [13]. Actually, the reliable way of studying erosive wear behavior is employing the experimental apparatus [14,15] but, there are theoretical relations which predict the erosive wear $[11,16]$.

\section{Erosion equation}

Finnie et al. [16] attributed the erosion wear to the two mechanisms: erosion due to cutting ensuing of the shear part of impact velocity and erosion due to plastic deformation and fatigue through the normal part of the impact velocity. The wear due to deformation occurs when the normal part of impingement velocity is larger than a specified value, threshold velocity, which depends on the parameters such as particle size, particle shape, particle hardness and target material properties. The model given by Finnie et al. [16] was improved by Arabnejad et al. [11] which gives the erosion volume due to cutting as follows: [11]

$$
\begin{aligned}
V_{c} & =C_{1} f_{s} \frac{m v^{q} \sin \theta[2 K \cos \theta-\sin \theta]}{2 K^{2}} \text { for } \theta \\
& <\tan ^{-1} K \\
V_{c} & =C_{1} f_{s} \frac{m v^{q} \cos ^{2} \theta}{2} \quad \text { for } \theta>\tan ^{-1} K .
\end{aligned}
$$

And the erosion volume due to deformation is given as follows: [11]

$$
V_{d}=C_{2} f_{s} m\left(v \sin \theta-v_{t s h}\right)^{2} .
$$

In above equations, $V c$ and $V d$ are erosion volume due to cutting and deformation respectively, $m$ is the particle mass, $v$ is the particle velocity, $F s$ is the sharpness factor of particle and $\theta$ is the incidence angle. $K$ is the ratio of normal and tangential contact surfaces due to impact. Total erosion wear will be as follow:

$$
m_{w}=\rho\left(V_{c}+V_{d}\right),
$$

where $m_{w}$ is the erosion mass and $\rho$ is target material density. For the deformation erosion, the effect of particle size is viewed in the threshold velocity value. Arabnejad et al. [17] gave the following relation between the particle size and threshold velocity:

$$
\frac{v_{t s h 2}}{v_{t s h 1}}=\left(\frac{R_{1}}{R_{2}}\right)^{3 / 2}
$$

in which $v_{\text {tsh1 }}$ and $v_{\text {tsh2 }}$ are threshold velocities of particle sizes $R 1$ and $R 2$ respectively. 

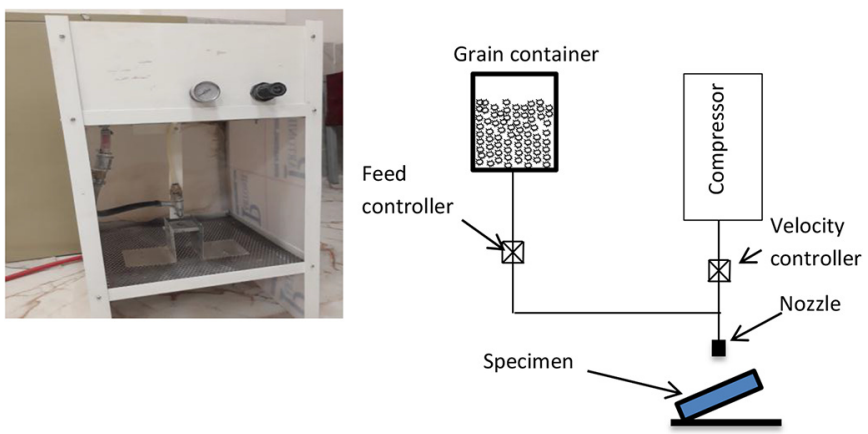

Figure 2. Schematic and image of the erosive wear test machine.

Table 1. Erosive wear test parameters

\begin{tabular}{ll}
\hline Velocity $(\mathrm{m} / \mathrm{s})$ & $20,30,40$ \\
Erosive grains $(\mu \mathrm{m})$ & $\mathrm{SiC}, 20-125,125-250$, \\
& $250-350$ \\
Impingement angle $(\mathrm{deg})$ & $30,45,60,90$ \\
Nozzle bore diameter $(\mathrm{mm})$ & 1.5 \\
Feed rate $(\mathrm{g} / \mathrm{min})$ & 40 \\
\hline
\end{tabular}

\section{Experimental rig}

Dry erosive test machines are designed such that the granular material is forced by the gas which is usually an air flow to provide the impingement on sample surface [18]. The test machine which is used in the present work is illustrated in Figure 2.

The air flow velocity is controlled by a pressure regulator and the particle feed rate is controlled by a valve in the grain pipe. An adjustable sample holder controls the specimen angle between $15^{\circ}$ and $90^{\circ}$.

The values of test parameters including the flow velocity, particle feed rate, impingement angle and grain size are given in Table 1.

\section{Samples}

The eroding particles are silica sand with three mesh sizes: 20-125, 125-250, 250-350 $\mu \mathrm{m}$. The specimens, as illustrated in Figure 3, are $30 \times 10 \times 3 \mathrm{~mm}$ AISI1020 with the hardness $95 \mathrm{HRB}$. The sample surface is finished manually by soft emery and washed by industrial solutions, before and after testing, to be cleaned of dust and debris. They are weighed by a balance with maximum capacity of $200 \mathrm{~g}$ and precise of $0.001 \mathrm{~g}$.

\section{Results}

\subsection{Experiment uncertainty}

Actually the experimental data without the error analysis and reproducibility are meaningless. After trying to

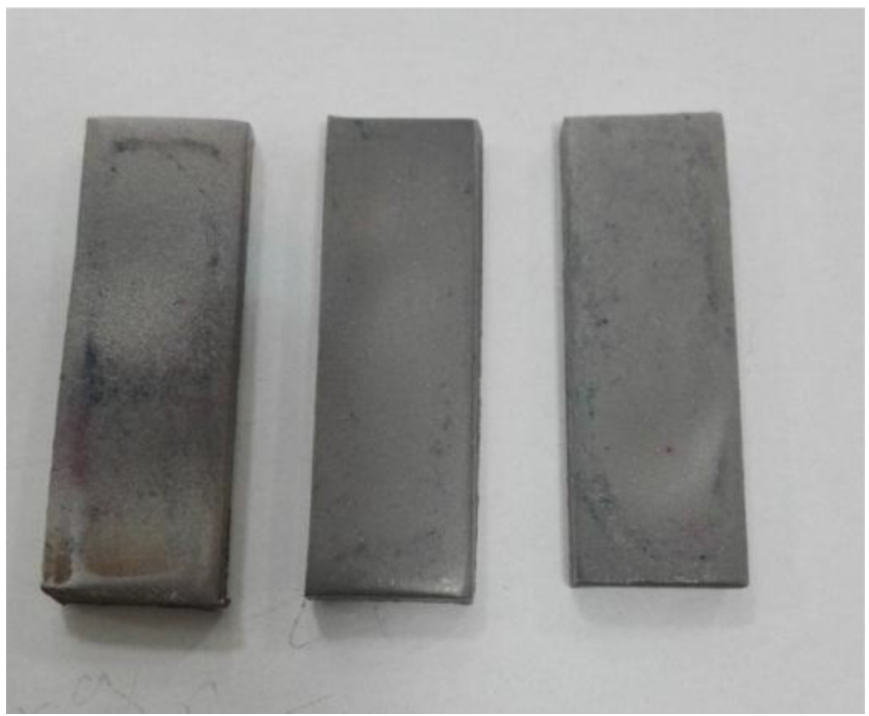

Figure 3. Samples for erosive wear tests.

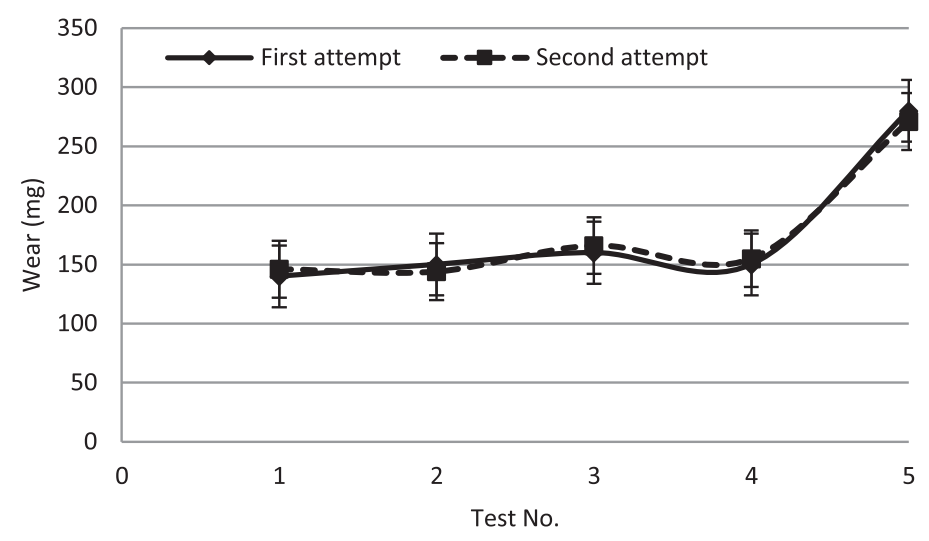

Figure 4. Wear measurements through first and second attempt of 5 tests at different conditions.

provide the test machine to have minimum noise factors and possibly precise measurements, one of tests was repeated several times and machine defects have been detected and corrected. Finally, to present the data reproducibility, 5 tests at the different test conditions have been repeated and shown the acceptable reproducibility. The results of the first attempt and second attempt for these 5 tests are given in Figure 4. According to this, the experiment uncertainty is about $4 \%$ which is between \pm 3 and $\pm 18 \mathrm{mg}$ for the present work data.

\subsection{Effect of impact velocity}

Impact velocity is an important parameter influencing the wear due to percussion in form of impact wear by large particles and in form of erosive wear by small particles [19]. Figure 5 illustrates the mass loss variation versus the flow velocity. It can be seen that, in almost all cases, the erosive wear increases by increasing the flow velocity. A relation between erosion wear rate and impact velocity has been reported as follows [9]:

$$
e=k_{1} v^{n} \text {. }
$$



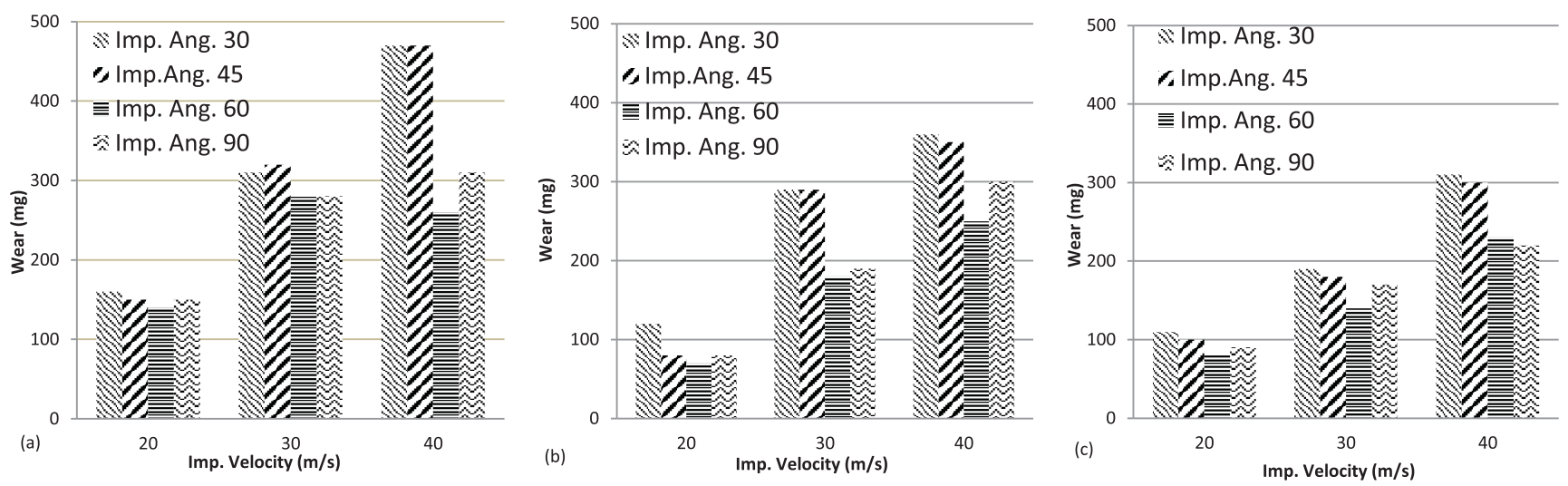

Figure 5. Mass loss at the different impact angles and different velocities with grain size (a) $20-125 \mu \mathrm{m}$, (b) $125-250 \mu \mathrm{m}$ (c) 250 $350 \mu \mathrm{m}$.

In which $e$ is the erosive wear rate, $v$ is the impingement velocity, $n$ is the velocity exponent and $k_{1}$ is a constant. $n$ has been reported to be between 2 and 3 for ductile materials [9]. Since it has been proved that there is a linear relation between the wear and impact energy [20-22], $n=2$ will be acceptable because the impact energy relates to the square of impact velocity. Present experimental data also confirm this. By fitting a trend line to the experimental data, it is observed that there is no unique behavior for variation of the mass loss versus the flow velocity at the different test conditions. In these trend lines the velocity exponent ranges between 1.5 and 2.14 and the average is 1.8. The velocity exponent is higher than 2 at the impact angles $45^{\circ}$ and $30^{\circ}$ but is about 1.3 at the impact angles $60^{\circ}$ and $90^{\circ}$. It means that there is an interaction between the flow velocity and impact angle. Flow velocity has the more effect on erosive wear at the impact angles $45^{\circ}$ and $30^{\circ}$ contrast to the other impact angles.

As reported in literature $[22,23]$, impact angle is an important parameter in erosive and impact wear mechanisms. The results of the present work also confirm that the impingement angle has an undeniable influence on the erosive wear. It has been reported that the maximum erosion wear of ductile materials occurs at the impact angle between $20^{\circ}$ and $30^{\circ}[24]$. Here, the wear maximizes at the impingement angles of $45^{\circ}$ and $30^{\circ}$ and minimizes at the impact angle of $60^{\circ}$. The erosive wear mechanism is due to a combination of normal impact load and sliding distance. Impact of a projectile on a target surface leaves a cavity where its dimension is an indication of the sliding and normal part of the impact velocity. The normal impacts provide the surface micro-cracks in brittle materials and fatigue spalls in ductile materials. Cutting occurs at low impact angles since the sliding portion of impact is more than the normal part. Since there are different wear responses to the normal load and sliding displacement for different materials, the critical impact angle is different for the different materials. Sliding distance is larger at the small impact angles so, the governing wear parameter is sliding distance. At the large impact angles, the governing wear parameter is the normal load. For the current specimens, the normal load and sliding distance provide the wear conditions which extreme at the impact angles of $30^{\circ}$ and $45^{\circ}$.

\subsection{Effect of grain size}

At the constant feed rate of grains in $(\mathrm{g} / \mathrm{min})$, grain size indicates the number of particles participating in erosive flow. There are more particles in flow with small grains than the flow with larger grains. Although the number of particles in a flow rate with small particles is more than the number of particles in a flow with larger particles, the wear caused by an individual larger particle is more than the wear caused by a smaller particle. The flow impact energy is evaluated by the following relation:

$$
E_{t}=\sum_{i=1}^{N} \frac{1}{2} m_{i} v_{i}^{2},
$$

where $E-t$ is the total impact energy over the specified test duration, $m i$ is the mass of single particle, $N$ is the number of particles and $v i$ is the impact velocity. Present work data, in all cases, indicated that the erosive wear made by the smaller particles $(20-125 \mu \mathrm{m})$ is more than the wear made by the larger particles $(125-250 \mu \mathrm{m}, 25-350 \mu \mathrm{m})$. However, the mass of the small particles is less than the mass of larger particles and so the lower individual impingement energy, but their number is more than the number of larger particles in a specified total mass. Since all experiments have been performed in same flow rate $(40 \mathrm{~g} /$ $\mathrm{min}$ ), it can be said that the total mass is same for all particle sizes (20-125, 125-250, 250-350) through $10 \mathrm{~min}$ of each test. On the other hand, it can also be said that at a constant air flow speed the velocity of small particles in air flow is higher than the velocity of larger particles. According to the more particles participating in flow and higher impact velocity, the wear made by the small particles is higher than the wear made by larger particles. The results of present study confirm this as illustrated in Figure 6 . 


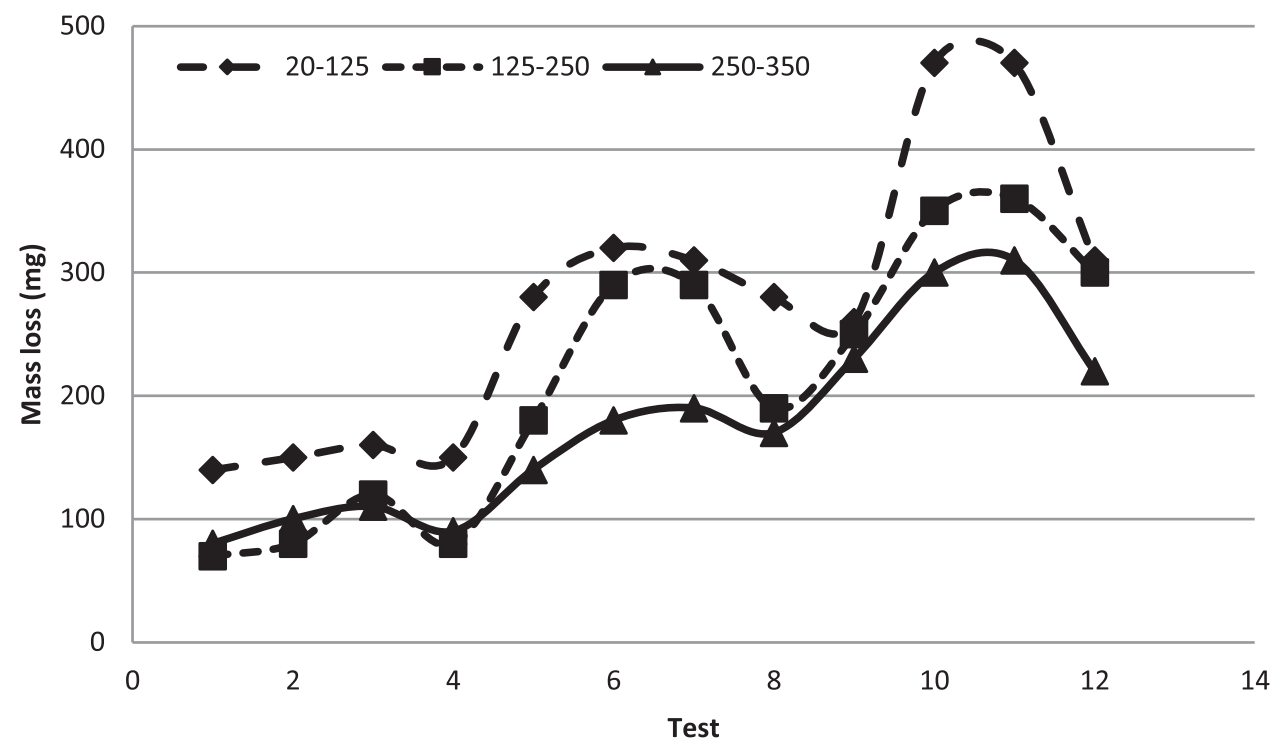

Figure 6. Comparison of erosive wear made by the different particle sizes.

Table 2. Factors of erosion equation for Carbon steel 1018 [11].

\begin{tabular}{lllll}
\hline$C_{1}$ & $q$ & $C_{2}$ & $K$ & $V_{\mathrm{tsh}}(\mathrm{m} / \mathrm{s})$ \\
\hline $5.9 \mathrm{E}-8$ & 2.42 & $4.25 \mathrm{E}-8$ & 0.5 & 5.5 \\
\hline
\end{tabular}

\subsection{Erosion equation factors}

Arabnejad et al. [11] determined the factors of erosion equation for Carbon steel 1018 as given in Table 2. The given threshold velocity in this table is for $150 \mu \mathrm{m}$ particles.

The properties of carbon steel 1020 are identical to those of carbon steel 1018. At first, the erosion wear of carbon steel 1020 is evaluated by the factors given in Table 2 which are for carbon steel 1018. The experimental data and evaluated erosion of carbon steel 1020, for several tests at the different conditions, are illustrated in Figure 7.

Tests in which high deviation between experimental data and model predictions is observed are indicated by arrows in Figure 7 . The deviations can be minimized by modification of factors in erosion model and selection of factors which give the better accordance between experimental data and erosion evaluations. Literature reported that the acceptable velocity exponent lies between 2 and 3 . It is 2.42 for AISI1018 as reported by [11] and is modified such that the highest accordance is achieved between experimental and theoretical results. Another modification is made on coefficients $C_{1}$ and $C_{2}$. However, the particle size effect comes into the model through threshold velocity relation (Eq. (5)), but, another discussion can be made based on the impact energy. The impact energy, $E=\frac{1}{2} m v^{2}$, depends on the particle velocity and particle size. From the erosion point of view, erosion due to the impact of particles with same impact energy is different at the different impact velocities and particle sizes. To tell this, another impact parameter, the contact duration through the impact, should be noticed. Relations given to evaluate contact duration include particle size and impact velocity [25]. The contact duration directly influences the peak contact force and depends on the particle and specimen properties. Moreover, the particle strength influences the erosion in cases the particle breakage occurs through the impingement and a portion of impact energy is wasted through the breakage. Inspection of particles after impact revealed that the average mesh size of particles decreased. Before impact, there was not any particle under $25 \mu \mathrm{m}$ in particle group $25-125 \mu \mathrm{m}$, any particle under $125 \mu \mathrm{m}$ in group 125$250 \mu \mathrm{m}$ and any particle under $250 \mu \mathrm{m}$ in group 250 $350 \mu \mathrm{m}$ but, screening revealed that there were noticeable under-size particles in particle groups after impact.

By using the modified factors in the erosion equation, better correspondence between the predicted and measured results was achieved.

The comparison of the experimental data and predicted erosion by the original factors [11] and modified ones is illustrated in Figure 8. It can be seen that in several tests the predictions have been closed to the measured values. The average difference between the evaluated erosion and the measured data is $38 \%$ and $26 \%$ in case of using factors of Tables 2 and 3, respectively. It means that the modified factors provide remarkable enhancement in predictive model. For tests 9,15 and 18 as illustrated in Figure 8, there are still high difference between model predictions and measured erosion. These three tests correspond to the flow velocity of $40 \mathrm{~m} / \mathrm{s}$. In fact, the evaluations have been done by the velocity value of $40 \mathrm{~m} / \mathrm{s}$. Through experiments, the grain velocity is provided by the air flow. It seems that the air flow was not enough to provide the velocity of $40 \mathrm{~m} / \mathrm{s}$ for some particles of the flow. For this reason the measured erosion in these three cases is clearly lower than the model evaluations. In other cases the clear enhancement is observed for model predictions. 


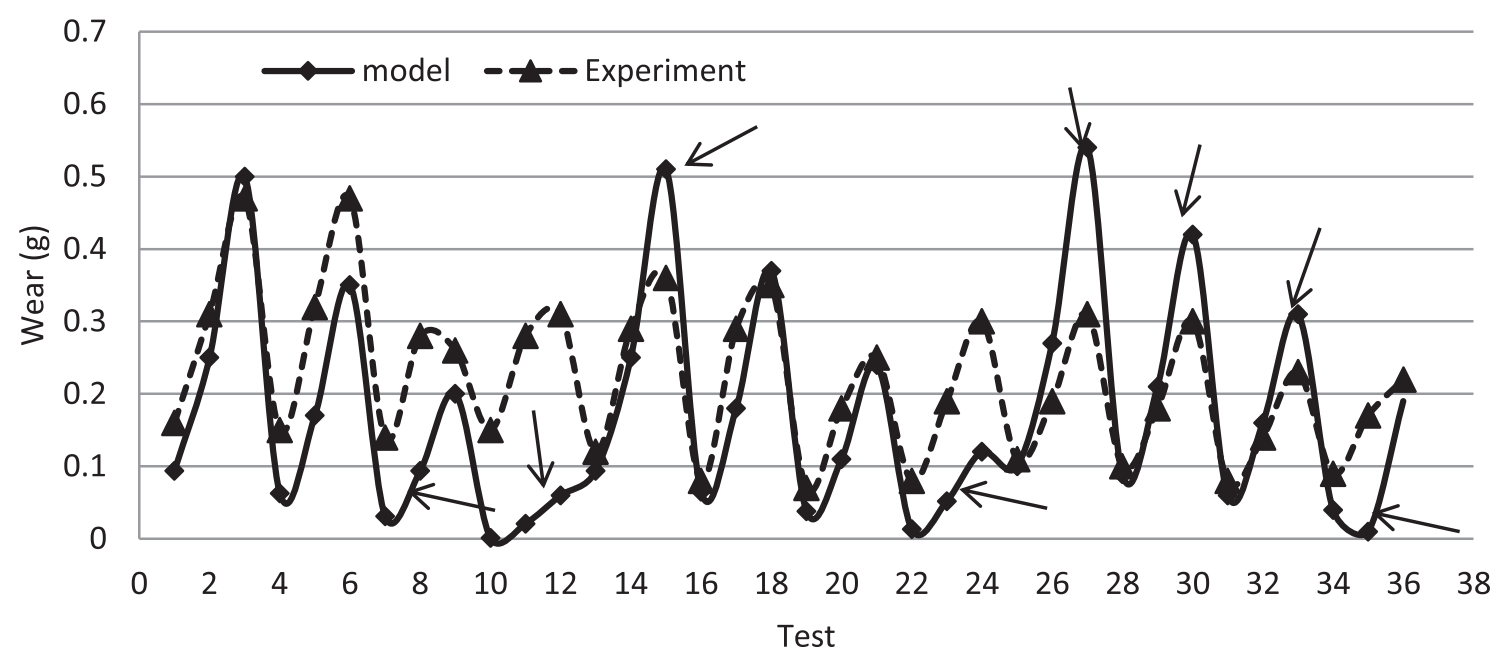

Figure 7. Experimental data and evaluated results of erosion of AISI1020.

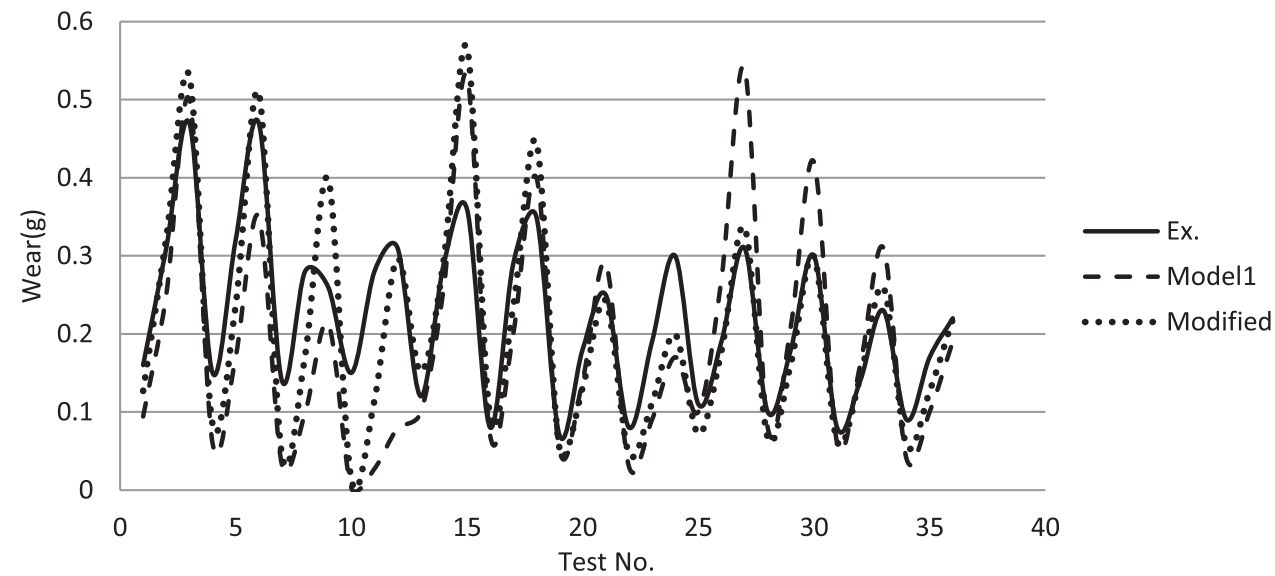

Figure 8. Comparison of measured data and predicted erosion by the modified factors.

Table 3. New factors of erosion equation for Carbon steel 1020.

\begin{tabular}{llllll}
\hline & $C_{1}$ & $q$ & $C_{2}$ & $K$ & $V_{\text {tsh }}(\mathrm{m} / \mathrm{s})$ \\
\hline $25-250 \mu \mathrm{m}$ & $1.1 \mathrm{E}-7$ & 2.31 & $0.83 \mathrm{E}-8$ & 0.5 & 5.5 \\
$250-350 \mu \mathrm{m}$ & $5.9 \mathrm{e}-8$ & 2.25 & $1.81 \mathrm{e}-7$ & 0.5 & 5.5 \\
\hline
\end{tabular}

\section{Conclusions}

Effects of influencing parameters on the erosive wear of AISI1020 steel was investigated by using a test machine. A variety of particle sizes of $\mathrm{SiC}$ was employed as eroding particles. A range of flow velocity was achieved by a regulator through the air supply pipe. The impingement angle was controlled by a movable holder in which the specimen was placed. Results indicated that the velocity is the most important governing parameter influencing the erosive wear. The erosive wear maximizes at the impact angles of $30^{\circ}$ and $45^{\circ}$. It was revealed that, at a constant flow rate, smaller particles result in more wear contrast to the larger particles. Erosive wear at the conditions of the present experiments was evaluated by using a theoretical relation. Deviation of the theoretical evaluations from the experimental data was reduced by using the appropriate coefficients in theoretical model for the present cases.

\section{Nomenclature}

$\begin{array}{ll}C_{1} & \text { Experimental wear coefficient } \\ C_{2} & \text { Experimental wear coefficient } \\ e & \text { Erosion wear rate }(\mathrm{kg} / \mathrm{s}) \\ E_{t} & \text { Total kinetic energy of flow }(\mathrm{J}) \\ f_{s} & \text { Shape factor } \\ K & \text { Ratio of normal and tangential contact surfaces } \\ & \text { due to impact } \\ k_{1} & \text { Experimental coefficient } \\ m, m_{i} & \text { Particle mass }(\mathrm{kg}) \\ m_{w} & \text { Erosion mass }(\mathrm{kg}) \\ n & \text { Experimental exponent } \\ N & \text { Number of particles } \\ q & \text { Experimental exponent } \\ R_{1}, R_{2} & \text { Particle size (mm) } \\ V_{c} & \text { Erosion due to cutting }\left(\mathrm{m}^{3}\right)\end{array}$


$V_{d} \quad$ Erosion due to deformation $\left(\mathrm{m}^{3}\right)$

$v, v_{i} \quad$ Particle velocity $(\mathrm{m} / \mathrm{s})$

$v_{t s h} \quad$ Velocity of erosion threshold $(\mathrm{m} / \mathrm{s})$

$\theta \quad$ Incidence angle

$\rho \quad$ Particle density $\left(\mathrm{kg} / \mathrm{m}^{3}\right)$

\section{References}

[1] K.V. Pool, C.K. Dharan, I. Finnie, Erosive wear of composite materials, Wear 107, 1-2 (1986)

[2] H.H. Tian, G.R. Addie, Experimental study on erosive wear of some metallic materials using Coriolis wear testing approach, Wear 258, 458-469 (2005)

[3] A. Bahri, N. Guermazi, K. Elleuch, M. Ürgen, On the erosive wear of $304 \mathrm{~L}$ stainless steel caused by olive seed particles impact: Modeling and experiments, Tribol. Int. 102, 608$619(2016)$

[4] G. Yadav, S. Tiwari, R. Jatola, N. Patel, Experimental study of erosive wear characteristics of various polypropylene polymers, Int. Res. J. Eng. Technol. 04, 2088-2090 (2017)

[5] A. Misra, I. Finnie, On the size effect in abrasive and erosive wear, Wear 65, 359-373 (1981)

[6] S. Bahadur, R. Badruddin, Erodent particle characterization and the effect of particle size and shape on erosion, Wear 138, 189-208 (1990)

[7] H.M. Clark, R.B. Hartwich, A re-examination of the "particle size effect'in slurry erosion, Wear 248, 147-161 (2001)

[8] A.W. Ruff, L.K. Ives, Measurement of solid particle velocity in erosive wear, Wear 35, 195-199 (1975)

[9] J. Zhang, Z. Han, W. Yin, H. Wang, C. Ge, J. Jiang, Numerical experiment of the solid particle erosion of bionic configuration blade of centrifugal fan, Acta Metallur. Sini. (English Letters) 26, 16-24 (2013)

[10] L. Shen, D. Eichner, S. van der Zwaag, C. Leyens, W.G. Sloof, Reducing the erosive wear rate of $\mathrm{Cr} 2 \mathrm{AlC}$ MAX phase ceramic by oxidative healing of local impact damage, Wear 358, 1-6 (2016)

[11] H. Arabnejad, A. Mansouri, S.A. Shirazi, B.S. Mc Luary, Evaluation of solid particle erosion equations and models for oil and gas industry application, Society for petroleum engineers, 2015
[12] G.R. Desale, B.K. Gandhi, S.C. Jain, Improvement in the design of a pot tester to simulate erosion wear due to solidliquid mixture, Wear 259, 196-202 (2005)

[13] B.K. Gandhi, S.V. Borse, Nominal particle size of multi-sized particulate slurries for evaluation of erosion wear and effect of fine particles, Wear 257, 73-79 (2004)

[14] W.J. Tsai, J.A. Humphrey, I. Cornet, A.V. Levy, Experimental measurement of accelerated erosion in a slurry pot tester, Wear 68, 289-303 (1981)

[15] G.R. Desale, B.K. Gandhi, S.C. Jain, Effect of erodent properties on erosion wear of ductile type materials, Wear 261, 914-921 (2006)

[16] I. Finnie, D.H. Mc Fadden, On the velocity dependence of the erosion of ductile metals by solid particles at low angles of incidence, Wear 48, 181-190 (1978)

[17] H. Arabnejad, A. Mansouri, S.A. Shirazi, B.S. Mc Luary, Development of mechanistic erosion equation for solid particles, Wear 332-333, 1044-1050 (2015)

[18] ASTM standard G76, Standard Test Method for Conducting Erosion Tests by Solid Particle Impingement Using Gas Jets, ASTM International, West Conshohocken, PA, 2013

[19] A.A. Hamed, W. Tabakoff, R.B. Rivir, K. Das, P. Arora, Turbine blade surface deterioration by erosion, J. Turbomach. 127, 445-452 (2005)

[20] H.F. Ding, F.M. Cui, X.D. Du, Effect of impact energy on impact wear property and mechanism of steels in corrosive environment, Trans. Mater. Heat Treat. 26, 55-60 (2005)

[21] M. Akhondizadeh, M.F. Mahani, M. Rezaeizadeh, S.H. Mansouri, Experimental investigation of the impact wear, Mech. Ind. 15, 39-44 (2014)

[22] H. Ashrafizadeh, F. Ashrafizadeh, A numerical 3D simulation for prediction of wear caused by solid particle impact, Wear 276, 75-84 (2012)

[23] A. Hamed, W. Tabakoff, R. Wenglarz. Erosion and deposition in turbomachinery, J. Propulsion Power 22, 350-360 (2006)

[24] H. Zhiwu, Z. Junqiu, G. Chao, W. Li, L. Ren, Erosion resistance of bionic functional surfaces inspired from desert scorpions, Langmuir 28, 2914-2921 (2012)

[25] W. Goldsmit, The Theory and Physical Behavior of Colliding Solids, Arnold, London, 1960

Cite this article as: M. Akhondizadeh, N. Afkhami, Determination of erosion equation factors of AISI1020 by experimental data, Mechanics \& Industry 21, 201 (2020) 